\title{
The Effect of Carrier Phase Jitter on MC-DS-CDMA
}

\author{
Heidi Steendam and Marc Moeneclaey \\ DIGCOM Research Group, Telecommunications and Information Processing (TELIN) department \\ Ghent University, St-Pietersnieuwstraat 41, B-9000 Gent, Belgium
}

$\{$ Heidi.Steendam,Marc.Moeneclaey\}@ telin.rug.ac.be

\begin{abstract}
In this contribution, we study the effect of carrier phase jitter on the performance of both uplink and downlink MC-DS-CDMA. We determine the resulting performance degradation in terms of the various system parameters. Assuming an AWGN channel, perfect power control and full load, it is shown that this degradation is independent of the number of carriers, of the spreading factor, and of the jitter spectrum shape, but only depends on the jitter variance.
\end{abstract}

\section{INTRODUCTION}

In the literature (see [1] and the references therein), different combinations of multicarrier modulation and codedivision multiple access (CDMA) have been investigated in the context of high-rate communication over dispersive channels. One of these combinations is the multicarrier direct-sequence CDMA (MC-DS-CDMA) technique, which is suitable for mobile radio [2].

In bandpass communication, the transmitter and the receiver contain a carrier oscillator for the upconversion (baseband to RF) and the downconversion (RF to baseband), respectively. When a small frequency offset between these oscillators is present, the performance of multicarrier systems like orthogonal frequency-division multiplexing (OFDM) and multicarrier CDMA (MC-CDMA) strongly degrades when the number of carriers increases [3]-[5]. In order to avoid the degradation associated with a carrier frequency offset, it was proposed in [4], [6] to correct the transmitter (uplink) or receiver (downlink) oscillator by means of a carrier synchronization mechanism. In these cases, the multicarrier system is affected only by the phase jitter resulting from the synchronizer.

In this contribution, we study the effect of carrier phase jitter on the performance of a MC-DS-CDMA system. First we consider the uplink transmission. From the corresponding results, the performance for downlink transmission is easily derived.

\section{SYSTEM DESCRIPTION}

The conceptual block diagram of an uplink multicarrier direct-sequence CDMA (MC-DS-CDMA) system is shown in Fig. 1. The sequence of data symbols to be transmitted by user $\ell$ at a rate $R_{s}$ is split into $N_{s}$ lower rate symbol sequences, each having a rate $\mathrm{R}_{\mathrm{s}} / \mathrm{N}_{\mathrm{s}}$ and modulating a different carrier of the multicarrier system. The data symbol $\mathrm{a}_{\mathrm{i}, \mathrm{k}, \ell}$, denoting the $\mathrm{i}^{\text {th }}$ symbol transmitted by user $\ell$ on carrier $\mathrm{k}$, is multiplied with the chip sequence $\left\{\mathrm{c}_{\mathrm{i}, \mathrm{n}, \ell} \mid \mathrm{n}=0, \ldots, \mathrm{N}_{\mathrm{c}}-1\right\}$ with spreading factor $\mathrm{N}_{\mathrm{c}}$, where $\mathrm{c}_{\mathrm{i}, \mathrm{n}, \ell}$ is the $\mathrm{n}^{\text {th }}$ chip of the sequence that spreads the data symbols transmitted by user $\ell$ during the $i^{\text {th }}$ symbol interval. The resulting samples are given by

$$
b_{i, k, n, \ell}=a_{i, k, \ell} c_{i, n, \ell} \quad n=0, \ldots, N_{c}-1 ; k \in I_{s} .
$$

The $\mathrm{N}_{\mathrm{c}}$ components of the spread data symbol $\mathrm{a}_{\mathrm{i}, \mathrm{k}, \ell}$, i.e. $\left\{\mathrm{b}_{\mathrm{i}, \mathrm{k}, \mathrm{n}, \ell}\right.$ $\left.\mid \mathrm{n}=0, \ldots, \mathrm{N}_{\mathrm{c}}-1\right\}$, are transmitted serially on the $\mathrm{k}^{\text {th }}$ carrier of an orthogonal multicarrier system. The spread data symbols are modulated on the orthogonal carriers using an $\mathrm{N}_{\mathrm{F}}$-point inverse fast Fourier transform (inverse FFT). Further, each FFT block at the inverse FFT output is extended with a cyclic prefix of $\mathrm{N}_{\mathrm{p}}$ samples, in order to avoid interference caused by a dispersive channel, resulting in a sequence of samples $\mathrm{s}_{\mathrm{i}, \mathrm{m}, \mathrm{n}, \ell}$, given by

$$
\begin{aligned}
s_{i, m, n, \ell}= & \frac{1}{\sqrt{N_{F}+N_{p}}} \sum_{k \in I_{s}} b_{i, k, n, \ell} e^{j 2 \pi \frac{k m}{N_{F}}} \\
m & =-N_{p}, \ldots, N_{F}-1
\end{aligned}
$$

In (2), m denotes the sample index within the extended FFT block. The transmitter feeds the samples $\mathrm{s}_{\mathrm{i}, \mathrm{m}, \mathrm{n}, \ell}$ at a rate $1 / \mathrm{T}=$ $\left(\mathrm{N}_{\mathrm{F}}+\mathrm{N}_{\mathrm{p}}\right) \mathrm{N}_{\mathrm{c}} \mathrm{R}_{\mathrm{s}} / \mathrm{N}_{\mathrm{s}}$ to a square-root raised-cosine transmit filter $\mathrm{P}(\mathrm{f})$ with rolloff factor $\alpha$ and impulse response $\mathrm{p}(\mathrm{t})$, yielding the time-domain signal $s_{\ell}(t)$

$$
s_{\ell}(t)=\sum_{i=-\infty}^{+\infty} \sum_{m=-N_{p}}^{N_{F}-1} \sum_{n=0}^{N_{c}-1} s_{i, m, n, \ell} p\left(t-t_{i, m, n}\right),
$$




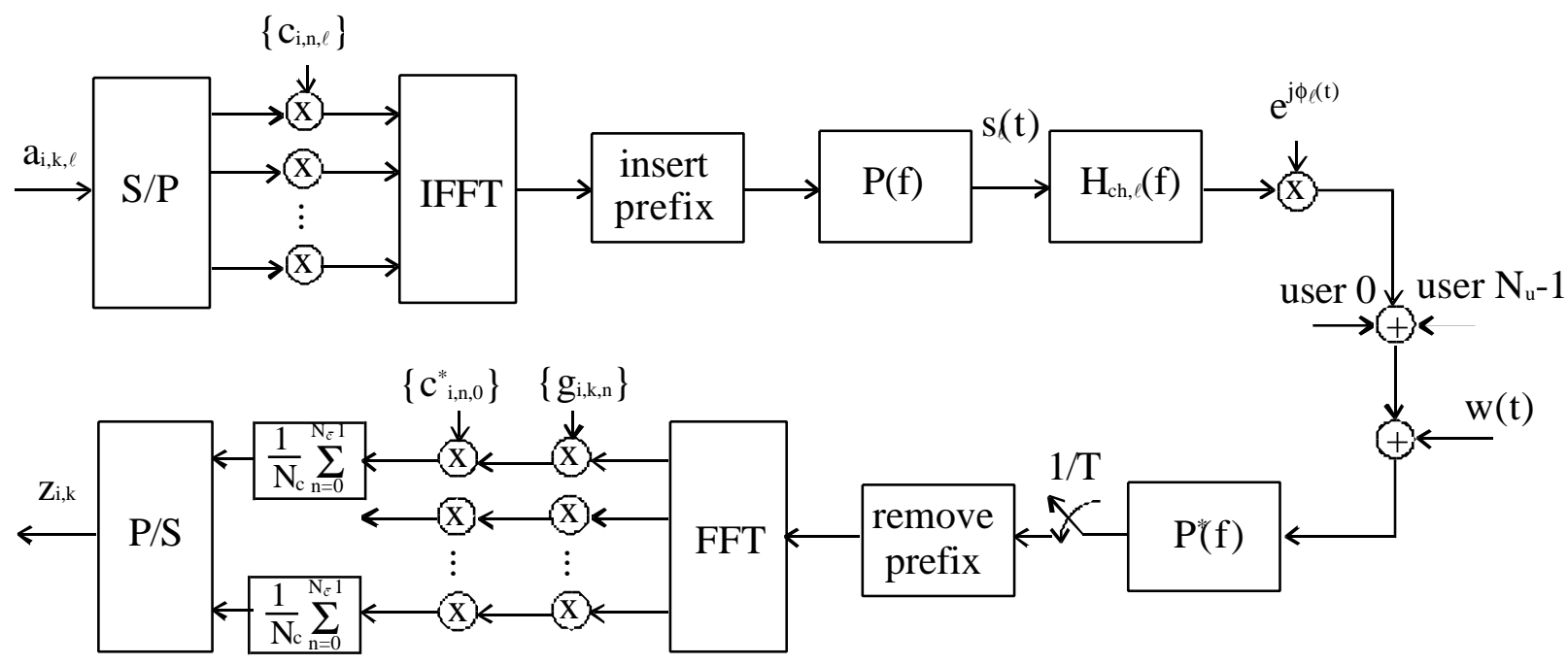

Figure 1: Conceptual block diagram of an uplink MC-DS-CDMA system

where $t_{i, m, n}=\left(m+\left(n+i N_{c}\right)\left(N_{F}+N_{p}\right)\right) T$. The carrier index $k$ corresponds to a carrier frequency $\mathrm{k} /\left(\mathrm{N}_{\mathrm{F}} \mathrm{T}\right)$. It is assumed that the carriers inside the rolloff area are not modulated, i.e. they have zero amplitude. Hence, only $\mathrm{N}$ of the $\mathrm{N}_{\mathrm{F}}$ available carriers are actually used $\left(\mathrm{N}_{\mathrm{s}} \leq(1-\alpha) \mathrm{N}_{\mathrm{F}}\right)$. Denoting $\mathrm{I}_{\mathrm{s}}$ as the set of carrier indices actually used and assuming $\mathrm{N}_{\mathrm{s}}$ to be odd, $\mathrm{I}_{\mathrm{s}}$ is given by $\mathrm{I}_{\mathrm{s}}=\left\{0, \ldots,\left(\mathrm{N}_{\mathrm{s}}-1\right) / 2\right\} \cup\left\{\mathrm{N}_{\mathrm{F}}-\left(\mathrm{N}_{\mathrm{s}}-1\right) / 2, \ldots, \mathrm{N}_{\mathrm{F}^{-}}-1\right\}$.

In a multiuser scenario, each user transmits a similar signal. As the base station must be able to separate the different user signals, each of the $\mathrm{N}_{\mathrm{u}}$ active users is assigned a unique spreading sequence. The spreading sequences considered in this contribution are orthogonal sequences, consisting of user-dependent Walsh-Hadamard (WH) sequences multiplied with a complex-valued random sequence that is common to all users. The maximum number of users equals $\mathrm{N}_{c}$, i.e. the number of WH sequences of length $\mathrm{N}_{\mathrm{c}}$.

The transfer function from the transmitter of user $\ell$ to the base station is denoted $\mathrm{H}_{\mathrm{ch}, \ell}(\mathrm{f})$. The output of the dispersive channel is disturbed by carrier phase jitter $\phi_{\ell}(\mathrm{t})$. The carrier phase jitter $\phi_{\ell}(\mathrm{t})$ can be modeled as a zero-mean stationary random process with jitter spectrum $S_{\phi \ell}(f)$ and jitter variance $\sigma_{\phi \ell}^{2}$. We assume the jitter processes vary slowly as compared to $\mathrm{T}$. The base station receives the sum of the signals transmitted by the different users, disturbed by additive white Gaussian noise (AWGN) w(t), with uncorrelated real and imaginary parts, each having a power spectral density of $\mathrm{N}_{0} / 2$.

The resulting signal is applied to the receiver filter, which is matched to the transmit filter, and sampled at a rate $1 / \mathrm{T}$. In the following, we concentrate on the detection of the data symbols transmitted by the reference user $\ell=0$. The receiver keeps from each FFT block the $\mathrm{N}_{\mathrm{F}}$ samples outside the cyclic prefix for further processing. The receiver consists of an $\mathrm{N}_{\mathrm{F}^{-}}$ point FFT, followed by one-tap equalizers $g_{i, k, n}$ that scale and rotate the $\mathrm{k}^{\text {th }}$ FFT output during the $\mathrm{n}^{\text {th }}$ FFT block in the $i^{\text {th }}$ symbol interval. Each equalizer output is multiplied with the corresponding chip of the reference user spreading sequence, and summed to obtain the sample $\mathrm{z}_{\mathrm{i}, \mathrm{k}}$ at the input of the decision device. The cyclic prefix length is assumed to exceed the duration of the impulse response of each of the filters $\mathrm{H}_{\ell}(\mathrm{f})=|\mathrm{P}(\mathrm{f})|^{2} \mathrm{H}_{\mathrm{ch}, \ell}(\mathrm{f}), \ell=0, \ldots, \mathrm{N}_{\mathrm{u}}-1$. In this case, the sample $\mathrm{z}_{\mathrm{i}, \mathrm{k}}$, which is used for the decision of the symbol $\mathrm{a}_{\mathrm{i}, \mathrm{k}, 0}$, is given by

$$
z_{i, k}=\sqrt{\frac{N_{F}}{N_{F}+N_{P}}} \sum_{\ell=0}^{N_{u}-1} \sum_{k^{\prime} \in I_{s}} a_{i, k^{\prime}, \ell} I_{i, k, k^{\prime}, \ell}+W_{i, k} \quad k \in I_{s},
$$

where $\mathrm{I}_{\mathrm{i}, \mathrm{k}, \mathrm{k}^{\prime}, \ell}$ denotes the contribution of the data symbol $\mathrm{a}_{\mathrm{i}, \mathrm{k}^{\prime}, \ell}$ to the sample $z_{i, k}$ at the input of the decision device. For small jitter variances $\left(\sigma_{\phi \ell}^{2}<<1\right)$, the approximation $\exp \left(j \phi_{\ell}(\mathrm{t})\right) \approx 1+\mathrm{j} \phi_{\ell}(\mathrm{t})$ can be used. In this case, $\mathrm{I}_{\mathrm{i}, \mathrm{k}, \mathrm{k}^{\prime}, \ell}$ can be approximated by

$$
I_{i, k, k^{\prime}, \ell}=\frac{H_{k^{\prime}, \ell}}{N_{c}} \sum_{n=0}^{N_{c}-1} g_{i, k, n} c_{i, n, 0}^{*} c_{i, n, \ell} A_{i, k, k^{\prime}, n, \ell}
$$

with

$$
A_{i, k, k^{\prime}, n, \ell}=\delta_{k, k^{\prime}}+\frac{1}{N_{F}} \sum_{m=0}^{N_{F}-1} e^{-j 2 \pi \frac{m\left(k-k^{\prime}\right)}{N_{F}}} j \phi_{\ell}\left(t_{i, m, n}\right)
$$

In (5), $\mathrm{H}_{\mathrm{k}^{\prime}, \ell}=\mathrm{H}_{\ell}\left(\bmod \left(\mathrm{k}^{\prime} ; \mathrm{N}_{\mathrm{F}}\right) / \mathrm{N}_{\mathrm{F}} \mathrm{T}\right) / \mathrm{T}$, where $\bmod \left(\mathrm{x} ; \mathrm{N}_{\mathrm{F}}\right)$ is the modulo- $\mathrm{N}_{\mathrm{F}}$ reduction of $\mathrm{x}$, yielding a result in the interval [- 
$\mathrm{N}_{\mathrm{F}} / 2 ; \mathrm{N}_{\mathrm{F}} / 2$ ]. The sample $\mathrm{z}_{\mathrm{i}, \mathrm{k}}$ (4) contains a useful contribution with coefficient $I_{i, k, k, 0}$. This useful component can be decomposed into an average useful component $\mathrm{E}\left[\mathrm{I}_{\mathrm{i}, \mathrm{k}, \mathrm{k}, 0}\right]$ and a zero-mean fluctuation $\mathrm{I}_{\mathrm{l}, \mathrm{k}, \mathrm{k}, 0}-\mathrm{E}\left[\mathrm{I}_{\mathrm{i}, \mathrm{k}, \mathrm{k}, 0}\right]$ about its average, i.e. the self-interference. For $k^{\prime} \neq k$, the quantity $I_{i, k, k^{\prime}, 0}$ corresponds to the intercarrier interference from other symbols transmitted by the reference user. The contributions $I_{i, k, k^{\prime}, \ell}(\ell \neq 0)$ from other users is multiuser interference. The power of the average useful component is denoted $\mathrm{P}_{\mathrm{U}_{\mathrm{k}}}$, while the sum of the powers of the self-interference, the intercarrier interference and the multiuser interference is denoted $P_{I_{k}}$. The additive noise contribution $\mathrm{W}_{\mathrm{i}, \mathrm{k}}$ in (4) has a power $\mathrm{P}_{\mathrm{N}_{\mathrm{k}}}$, given by

$$
P_{N_{k}}=E\left[\left|W_{i, k}\right|^{2}\right]=N_{0} \frac{1}{N_{c}} \sum_{n=0}^{N_{c}-1}\left|g_{i, k, n}\right|^{2} .
$$

The equalizer coefficients are selected such that the coefficient $E\left[I_{i, k, k, 0}\right]$ of the average useful component equals 1. Assuming that accurate estimates of $\mathrm{H}_{\mathrm{k}, 0}$ are available, the equalizer coefficients yield $\mathrm{g}_{\mathrm{i}, \mathrm{k}, \mathrm{n}}=1 / \mathrm{H}_{\mathrm{k}, 0}$.

\section{PERFORMANCE DEGRADATION}

The signal-to-noise ratio (SNR) at the input of the decision device is defined as the ratio of the power of the average useful component to the sum of the powers of the remaining components, i.e. $\mathrm{SNR}_{\mathrm{k}}(\phi)=\mathrm{P}_{\mathrm{U}_{\mathrm{k}}} /\left(\mathrm{P}_{\mathrm{N}_{\mathrm{k}}}+\mathrm{P}_{\mathrm{I}_{\mathrm{k}}}\right)$. In the absence of carrier phase jitter, the $\mathrm{SNR}$ reduces to $\operatorname{SNR}_{\mathrm{k}}(0)=$ $\left(\mathrm{E}_{\mathrm{sk}, 0} / \mathrm{N}_{0}\right)\left|\mathrm{H}_{\mathrm{k}, 0}\right|^{2}\left(\mathrm{~N}_{\mathrm{F}} /\left(\mathrm{N}_{\mathrm{F}}+\mathrm{N}_{\mathrm{P}}\right)\right)$, where $\mathrm{E}_{\mathrm{sk}, \ell}=\mathrm{E}\left[\left|\mathrm{a}_{\mathrm{i}, \mathrm{k}, \ell}\right|^{2}\right]$ is the energy per symbol transmitted by user $\ell$ on the $\mathrm{k}^{\text {th }}$ carrier. The degradation (in $\mathrm{dB}$ ) caused by the frequency offset is then given by $\operatorname{Deg}_{k}=10 \log \left(\operatorname{SNR}_{k}(0) / \operatorname{SNR}_{k}(\phi)\right)$, i.e.

$D e g_{k}=10 \log \left(1+S N R_{k}(0)\left(A_{0}+\sum_{\substack{k^{\prime} \in I_{s} \\ k^{\prime} \neq k}} A_{k^{\prime}}+\sum_{\ell=1}^{N_{u^{\prime}}-1} \sum_{k^{\prime} \in I_{s}} B_{k^{\prime}, \ell}\right)\right)$,

where

$$
\begin{gathered}
A_{k^{\prime}}=\frac{E_{s_{k^{\prime}, 0}}}{E_{s_{k, 0}}}\left|\frac{H_{k^{\prime}, 0}}{H_{k, 0}}\right|^{2} \int_{-\infty}^{+\infty} S_{\phi_{0}}(f) X_{1}(f) d f, \\
B_{k^{\prime}, \ell}=\frac{1}{N_{c}-1} \frac{E_{s_{k^{\prime}, \ell}}}{E_{s_{k, 0}}}\left|\frac{H_{k^{\prime}, \ell}}{H_{k, 0}}\right| \int_{-\infty}^{+\infty} S_{\phi_{\ell}}(f) X_{2}(f) d f,
\end{gathered}
$$

$$
\begin{gathered}
X_{1}(f)=\left|D_{N_{c}}\left(\left(N_{F}+N_{p}\right) f T\right)^{2}\right| D_{N_{F}}\left(f T+\frac{k^{\prime}-k}{N_{F}}\right)^{2}, \\
X_{2}(f)=\left(1-\mid D_{N_{c}}\left(\left(N_{F}+N_{p}\right) f T\right)^{2}\right) D_{N_{F}}\left(f T+\frac{k^{\prime}-k}{N_{F}}\right)^{2}, \\
D_{M}(x)=\frac{1}{M} \sum_{m=0}^{M-1} e^{j 2 \pi m x}=e^{j \pi(M-1) x} \frac{\sin (\pi M x)}{M \sin (\pi x)} .
\end{gathered}
$$

In (8), the quantity $A_{0}$ corresponds to the self-interference. For $k^{\prime} \neq k$, the quantity $A_{k^{\prime}}$ corresponds to the intercarrier interference at the input of the decision device of carrier $\mathrm{k}$ caused by the symbol transmitted by the considered user on carrier $\mathrm{k}^{\prime}$. For $\ell^{\prime} \neq 0$, the quantity $\mathrm{B}_{\mathrm{k}^{\prime}, \ell}$ corresponds to the multiuser interference caused by the symbol transmitted by user $\ell$ on carrier k'.

To clearly isolate the effect of the carrier phase jitter, we consider the case of perfect per carrier power control (i.e. $\mathrm{E}_{\mathrm{sk}, \ell}\left|\mathrm{H}_{\mathrm{k}^{\prime}, \ell}\right|^{2}=\mathrm{E}_{\mathrm{s}}$ for $\left.\mathrm{k} \in \mathrm{I}_{\mathrm{s}}, \quad \ell=0, \ldots, \mathrm{N}_{\mathrm{u}}-1\right)$, and the load is maximum $\left(\mathrm{N}_{\mathrm{u}}=\mathrm{N}_{\mathrm{c}}\right)$. Furthermore, we assume that all jitter processes have the same jitter spectrum $S_{\phi \ell}(f)=S_{\phi}(f)$. In this case, the degradation is given by

$$
\begin{aligned}
\operatorname{Deg}_{k}= & 10 \log (1+\operatorname{SNR}(0) \\
& \left.\sum_{k \in I_{s}} \int_{-\infty}^{+\infty} S_{\phi}(f) \mid D_{N_{F}}\left(f T+\frac{k^{\prime}-k}{N_{F}}\right)^{2} d f\right)^{\prime},
\end{aligned}
$$

where $\operatorname{SNR}(0)=\left(\mathrm{E}_{\mathrm{S}} / \mathrm{N}_{0}\right)\left(\mathrm{N}_{\mathrm{F}} /\left(\mathrm{N}_{\mathrm{F}}+\mathrm{N}_{\mathrm{P}}\right)\right)$. The summation over $\mathrm{k}^{\prime}$ in (14) corresponds to the summation over the $\mathrm{N}_{\mathrm{s}}$ modulated carriers. Taking into account that $\left|\mathrm{D}_{\mathrm{M}}(\mathrm{x})\right|$ has a large peak for integer values of $x$, it follows from (14) that the interference from symbols transmitted on carrier $\mathrm{k}^{\prime}$ is mainly caused by jitter components near the frequency $f=\left(k-k^{\prime}\right) /\left(N_{F} T\right)+q / T$ $(q=0, \pm 1, \ldots)$.

A simple upper bound on the degradation (14) is obtained by extending the summation interval to all available carriers, i.e. $\mathrm{k}^{\prime}=0, \ldots, \mathrm{N}_{\mathrm{F}}-1$. This yields

$$
\operatorname{Deg} \leq 10 \log \left(1+\operatorname{SNR}(0) \sigma_{\phi}^{2}\right)
$$

where the jitter variance is given by 


$$
\sigma_{\phi}^{2}=\int_{-\infty}^{+\infty} S_{\phi}(f) d f
$$

The upper bound (15) on the degradation is independent of the carrier index $\mathrm{k}$ and the shape of the jitter spectrum, but only depends on the jitter variance. Furthermore, the bound is independent of the number of carriers $\mathrm{N}_{\mathrm{s}}$ and of the spreading factor $\mathrm{N}_{\mathrm{c}}$. The upper bound is reached when all carriers are modulated $\left(\mathrm{N}_{\mathrm{s}}=\mathrm{N}_{\mathrm{F}} ; \alpha=0\right)$. When $\alpha>0$, the upper bound yields an accurate approximation for the actual degradation for the carriers near the center of the signal band. The bound (15) is shown in Fig. 2 as function of the jitter variance. For small jitter variances, the degradation is proportional to $\sigma_{\phi}^{2}$.

The above derivations hold for uplink transmission. In the downlink, the channel transfer function, the transmit power and the phase jitter are the same for all user signals. Hence, the degradation for downlink transmission is obtained by making the following substitution in the corresponding expression for uplink transmission: $\mathrm{H}_{\mathrm{ch}, \ell}(\mathrm{f})=\mathrm{H}_{\mathrm{ch}}(\mathrm{f}), \mathrm{E}_{\mathrm{sk} \ell}=\mathrm{E}_{\mathrm{sk}}$, $S_{\phi \ell}(f)=S_{\phi}(f)$, for $\ell=0, \ldots, N_{u}-1$. For an ideal channel, maximum load and the same transmit energy per symbol on all carriers, (14)-(15) are also valid for the downlink.

\section{CONCLUSIONS}

In this contribution, we have investigated the sensitivity of uplink and downlink MC-DS-CDMA to carrier phase jitter. We have determined the degradation of the SNR at the input of the decision device in terms of the system parameters. On an ideal channel, for the maximum load and perfect power control, this degradation is independent of the number of carriers, of the spreading factor, and of the jitter spectrum shape but only depends on the jitter variance. Under these assumptions, the degradation for uplink and downlink transmission are the same. These results are similar to those obtained for OFDM and MC-CDMA in [7].

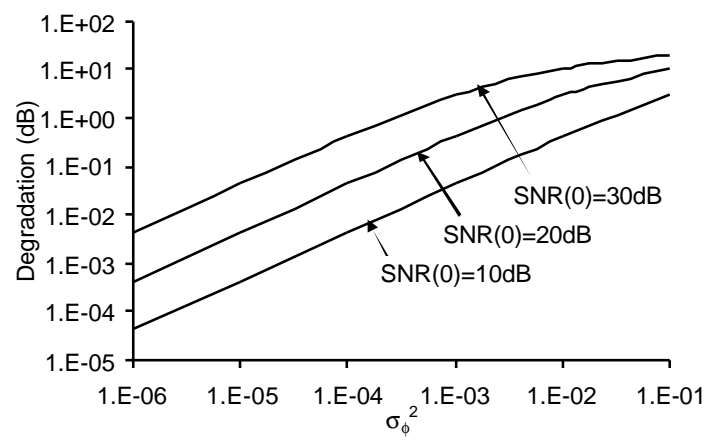

Figure 2: Degradation caused by carrier phase jitter $\left(\mathrm{N}_{\mathrm{u}}=\mathrm{N}_{\mathrm{c}}\right.$,

$$
\left.\mathrm{E}_{\mathrm{sk}, \ell}\left|\mathrm{H}_{\mathrm{k}, \ell}\right|^{2}=\mathrm{E}_{\mathrm{s}}\right)
$$

\section{REFERENCES}

[1] S. Hara, R. Prasad, "Overview of multicarrier CDMA", IEEE Communications Magazine, Dec 1997, Vol. 35, No. 12, pp. 126-133

[2] V.M. DaSilva, E.S. Sousa, "Performance of orthogonal CDMA sequences for quasi-synchronous communication systems", Proceedings IEEE ICUPC'93, Ottawa, Canada, Oct. 1993, pp. 995999

[3] T. Pollet, M. Van Bladel, M. Moeneclaey, "BER sensitivity of OFDM systems to carrier frequency offset and Wiener phase noise", IEEE Trans. on Comm., Vol. 43, no. 2/3/4, Feb/Mar/Apr 93, pp. 191-193

[4] H. Steendam, M. Moeneclaey, "The effect of synchronisation errors on MC-CDMA performance", Proceedings International Conference on Communications ICC'99, Vancouver, Canada, June 6-10, 1999, Paper S38.3, pp. 1510-1514

[5] L. Tomba and W.A. Krzymien, "Effect of carrier phase noise and frequency offset on the performance of multicarrier CDMA systems", Proceedings International Conference on Communications ICC'96, Dallas TX, Jun 1996, Paper S49.5, pp. 1513-1517

[6] T. Pollet, M. Moeneclaey, I. Jeanclaude, H. Sari, "Effect of carrier phase jitter on single-carrier and multi-carrier QAM systems", Proceedings ICC 1995, Seattle WA, Jun 95, Paper S29.4, pp. 10461050

[7] H. Steendam, M. Moeneclaey, "Sensitivity of OFDM and MC-CDMA to carrier phase errors", Proceedings th Symposium on Vehicular Technology and Communications 1998, Oct 12-13, Brussels, Belgium 